
Approximate Solutions by Optimal Perturbation Iteration Method

\author{
Sinan DENIZ \\ Manisa Celal Bayar University, Faculty of Arts \& Science, Department of Mathematics, 45140, Manisa/TURKEY. \\ e-posta: sinan.deniz@cbu.edu.tr ORCIDID: https://orcid.org/0000-0002-8884-3680
}

Geliş Tarihi: 22.11.2019

Kabul Tarihi: 19.02 .2020

\begin{tabular}{|c|c|}
\hline Keywords & Abstract \\
\hline $\begin{array}{l}\text { Optimal perturbation } \\
\text { iteration technique; } \\
\text { system of partial } \\
\text { differential equations; } \\
\text { solitons; semi- } \\
\text { analytical method }\end{array}$ & $\begin{array}{l}\text { We try to find the semi-analytical approximate solutions for the system of partial differential equations } \\
\text { by using a newly developed scheme. The optimal perturbation iteration method is introduced and then } \\
\text { applied to a newly modified coupled Drinfel'd-Sokolov-Wilson equation. Classical perturbation theory } \\
\text { and optimization techniques are combined to construct this method. We will deeply analyze an example } \\
\text { to prove the power of the proposed method, namely the optimal perturbation iteration method. With } \\
\text { the theorem and applications, we see that the present study shows that the new method converges } \\
\text { fast to the accurate analytical solutions of the considered equations at even the first two-three } \\
\text { iterations. }\end{array}$ \\
\hline
\end{tabular}

\title{
İkili Drinfel'd-Sokolov-Wilson Denklemlerinin Modifiyesi ve Yaklaşık Çözümleri İçin Optimal Perturbasyon İterasyon Metodu
}

\author{
Anahtar kelimeler \\ Optimal perturbasyon \\ iterasyon yöntemi; \\ Kısmi diferansiyel \\ denklemler sistemi; \\ solitonlar; yarı-analitik \\ metotlar
}

\begin{abstract}
Öz
Bu araştırma makalesinde, kısmi diferansiyel denklemler sistemi için yeni geliştirilen bir metot yardımıyla yarı analitik çözümler bulmaya çalışıyoruz. Optimal perturbasyon iterasyon yöntemini tanıtıyor ve sonra yeniden modifiye edilen ikili Drinfel'd-Sokolov-Wilson denklemine uyguluyoruz. Klasik perturbasyon teorisi ve optimizasyon teknikleri birleştirilerek bu yöntemi inşa ediyoruz. Optimal perturbasyon iterasyon olarak önerilen metodun gücünü göstermek için özel bir örneği derinlemesine irdeliyoruz. Teorem ve uygulamalar önerilen tekniğin ele alınan denklemler için iterasyonun daha ilk basamaklarında tam çözüme hızlı bir şekilde yaklaştığını göstermektedir.
\end{abstract}

\section{Introduction}

The importance of nonlinear system of partial differential equations (NPDEs) is obvious in science and engineering. Similarly, the solitons and their equations (in terms of NPDEs) are distinguished subjects in the field of physics and applied sciences. In recent years, a large number of physical or mental efforts have been made to scrutinize various nonlinear soliton equations. The exact analytical solutions of nonlinear wave equations assist to comprehend the behavior and characteristics of nonlinear equations of solitons. Because of that, seeking analytical or approximate solutions of nonlinear wave equations have been always an important and interesting subject. Up to now, there have been many methods to investigate these types of NPDEs. Wadati Miki and Kimiaki Konno deeply analyzed some relationships among inverse method, Bäcklund transformation and an infinite number of conservation laws on the NPDEs (Miki and Konno 1975). Guo Boling and their co-authors have examined nonlinear Schrödinger equation with the help of generalized Darboux transformation and rogue wave solutions (Boling et 
al. 2012). Manafian and Lakestani proved the solitary wave and periodic wave solutions for variants of the KdV-Burger equation (Manafian and Lakestani 2013). Manafian and Zamanpour used Exp-function method for analytical treatment of the coupled Higgs equation and the Maccari system (Manafian and Zamanpour 2013). In 2007, Shang have proposed Backlünd transformation, Lax pairs and explicit exact solutions for the shallow water waves equation (Shang 2007). Many other techniques can also be given to deal with these types of NPDEs (Matveed and Salle 1991, Malfliet 1992, Shen and Pan 2003, Inan 2019).

In this section, we construct some algorithms by using optimal perturbation iteration method for the following system of partial differential equations (PDE):

$u_{t}+p v v_{x}+v^{2} v_{x}=0$,

$v_{t}+q v_{x x x}+r u v_{x}+s v u_{x}=0$

where $p, q, r$, sare some nonzero parameters. The last term in the first equation can be used to decrease the oscillations of the solitons and it can be used to model a modified coupled Drinfel' $d$ Sokolov-Wilson equation. These types of equations are usually encountered in many different fields of science and engineering. Fan Engui and Hongqing Zhang have used homogeneous balance method to analyze this type of problem (Fan and Zhang 1998). Abdul-Majid Wazwaz found multiple-soliton solutions by Hirota's bilinear method and by the tanh-coth method (Wazwaz 2007). Let us suppose that we have following initial conditions for the Eq. (1):

$$
\begin{aligned}
& u(x, 0)=e^{x} \\
& v(x, 0)=e^{-x}
\end{aligned}
$$

In order to deal with these types of PDEs, some researchers have developed certain efficient methods (Baskonuş et al., 2013; Inç, 2008; Pandır et al.,2017; Tülüce et al.,2016). In the next section we show how to obtain a reliable iterative techique for solving these types of systems.

\footnotetext{
2. OPIM for the System of Partial Differential Equations
}

Optimal perturbation iteration method (OPIM) and optimal perturbation iteration algorithms or shortly OPIAs have been lately established with the help of the classical perturbation theory (Bildik and Deniz, 2017; Bildik and Deniz, 2018). OPIAs and modifications are all devised to deal with the nonlinear problems. Because there is no need to deal with linear differential equations. OPIM has been implemented to wide range of physical problems such as heat transfer, Burger's, LaneEmden type equations, etc (Deniz, 2017; Bildik and Deniz, 2017; Bildik and Deniz, 2018). We now try to create an algorithm for the aforementioned problem:

a) The Eqs. (1) can be reconsidered with a perturbation parameter $\varepsilon$ as:

$F_{1}\left(u_{t}, v_{x}, v, \varepsilon\right)=0$

$F_{2}\left(v_{x x x}, u_{x}, v_{t}, v_{x}, u, \varepsilon\right)=0$

and $\varepsilon$ can be furnished into the Eq. (3) :

$$
\begin{aligned}
& F_{1}\left(u_{x}, u_{t}, v_{x}, \varepsilon\right)=u_{t}+p \varepsilon v v_{x}+\varepsilon v^{2} v_{x}=0 \\
& F_{2}\left(u_{x x x}, u_{x}, v_{t}, v_{x}, \varepsilon\right)= \\
& v_{t}+q v_{x x x}+\varepsilon\left(r u v_{x}+s v u_{x}\right)=0
\end{aligned}
$$

Now, to eliminate the linear terms, (4) can be separated as:

$F_{1}=S_{1}+R_{1}$

$F_{2}=S_{2}+R_{2}$.

Doing the above modification will yield easier calculations. We denote generally linear part as $S$. Also, to represent the nonlinear terms we use $R$. One actually will interest with $R$. For example, we can select

$$
R\left(v_{x}, v, \varepsilon\right)=\varepsilon p v v_{x}+\varepsilon v^{2} v_{x}
$$

and

$$
S\left(u_{t}\right)=u_{t}
$$


for the considered PDE.

b) To start iterations, we need first straightforward perturbation series and the following approximations:

$$
\begin{aligned}
& u_{n+1}=u_{n}+\varepsilon\left(u_{c}\right)_{n} \\
& v_{n+1}=v_{n}+\varepsilon\left(v_{c}\right)_{n}
\end{aligned}
$$

where $\left(u_{c}\right)_{n}$ and $\left(v_{c}\right)_{n}$ are the $n$th correction terms. We then replace equations (9i) - (9ii) into (4) to get an algorithm for OPIM. After substituting, one requires to use the Taylor series of these equations at $\varepsilon=0$ as can be calculated:

$$
\begin{aligned}
& F+F_{u_{t}}\left(\left(u_{c}\right)_{n}\right)_{t} \varepsilon+F_{v_{x}}\left(\left(v_{c}\right)_{n}\right)_{x} \varepsilon \\
& +F_{v}\left(\left(v_{c}\right)_{n}\right) \varepsilon+F_{\varepsilon} \varepsilon=0 \\
& F+F_{v_{t}}\left(\left(v_{c}\right)_{n}\right)_{t} \varepsilon+F_{v_{x}}\left(\left(v_{c}\right)_{n}\right)_{x} \varepsilon \\
& +F_{v_{x x x}}\left(\left(v_{c}\right)_{n}\right)_{x x x} \varepsilon+F_{u}\left(\left(u_{c}\right)_{n}\right)_{x} \varepsilon+F_{\varepsilon} \varepsilon=0
\end{aligned}
$$

or equivalently

$$
\begin{aligned}
& R+R_{u_{t}}\left(\left(u_{c}\right)_{n}\right)_{t} \varepsilon+R_{v_{x}}\left(\left(v_{c}\right)_{n}\right)_{x} \varepsilon \\
& +R_{v}\left(\left(v_{c}\right)_{n}\right)+R_{\varepsilon} \varepsilon=-S \\
& R+R_{v_{t}}\left(\left(v_{c}\right)_{n}\right)_{t} \varepsilon+R_{v_{x}}\left(\left(v_{c}\right)_{n}\right)_{x} \varepsilon \\
& +R_{v_{x x x}}\left(\left(v_{c}\right)_{n}\right)_{x x x} \varepsilon+R_{u}\left(\left(u_{c}\right)_{n}\right)_{x} \varepsilon+R_{\varepsilon} \varepsilon=-S
\end{aligned}
$$

The following notations represents the above computations:

$R_{\varepsilon}=\frac{\partial R}{\partial \varepsilon}, R_{u_{t}}=\frac{\partial R}{\partial u_{t}}$,

$R_{u_{x}}=\frac{\partial R}{\partial u_{x}}, R_{v_{x}}=\frac{\partial R}{\partial v_{x}}, \cdots$

By doing the essential computations for the considered problem, one has:

$$
\begin{aligned}
& \left(\left(u_{c}\right)_{n}\right)_{t}=-p\left(v_{n}\right)_{x}\left(v_{n}\right) \\
& \left(\left(v_{c}\right)_{n}\right)_{t}=-q\left(v_{n}\right)_{x x x}-r\left(v_{n}\right)_{x}\left(u_{n}\right)-s\left(u_{n}\right)_{x}\left(v_{n}\right)
\end{aligned}
$$

The above expressions are the optimal perturbation iteration algorithms (OPIA) for the system of partial differential equations. To initiate the OPIA iterations, $u_{0}$ and $v_{0}$ (initial functions) are chosen suitably with the help of the given conditions.

c) Using the OPIAs for the system of PDE, we can get the first $\left(u_{c}\right)_{n}$ or $\left(u_{c}\right)_{0}$. If one needs more accurate results or optimal solutions, unknown parameters can be used as:

$$
\begin{aligned}
& u_{n+1}=u_{n}+P_{n}\left(u_{c}\right)_{n} \\
& v_{n+1}=v_{n}+P_{n}\left(v_{c}\right)_{n}
\end{aligned}
$$

where $P_{0}, P_{1}, P_{2}, \ldots$ are named as convergencecontrol parameters. With the aid of those constants, one can check and set the convergence of the solutions. By iterating, one gets

$$
\begin{aligned}
& u_{1}=u\left(x, t ; P_{0}\right)=u_{0}+P_{0}\left(u_{c}\right)_{0} \\
& v_{1}=v\left(x, t ; P_{0}, P_{1}\right)=v_{1}+P_{1}\left(v_{c}\right)_{1} \\
& \quad \vdots \\
& u_{m}\left(x, t ; P_{0}, \ldots, P_{m-1}\right)=u_{m-1}+P_{m-1}\left(u_{c}\right)_{m-1} \\
& v_{m}\left(x, t ; P_{0}, \ldots, P_{m-1}\right)=v_{m-1}+P_{m-1}\left(v_{c}\right)_{m-1}
\end{aligned} .
$$

d) When $u_{m}, v_{m}$ are substituted intothe equation (4), the overall problem will become:

$$
\begin{aligned}
& R e_{1}\left(x, t ; P_{0}, \ldots, P_{m-1}\right)= \\
& F_{1}\left(\left(u_{m}\right)_{t},\left(v_{m}\right)_{x}, v_{m}, \varepsilon\right)=0, \\
& R e_{2}\left(x, t ; P_{0}, \ldots, P_{m-1}\right) \\
& =F_{2}\left(\left(v_{m}\right)_{x x x},\left(u_{m}\right)_{x},\left(v_{m}\right)_{t},\left(v_{m}\right)_{x}, u_{m}, \varepsilon\right)=0
\end{aligned}
$$

Apparently, when residuals are equal to zero, then our results are actually the exact solutions. Otherwise, we need minimize the functional as:

$J_{1}\left(P_{0}, \ldots, P_{m-1}\right)=\int_{0}^{T} \int_{a}^{b} \operatorname{Re}_{1}{ }^{2}\left(x, t ; P_{0}, \ldots, P_{m-1}\right) d x d t$ $J_{2}\left(P_{0}, \ldots, P_{m-1}\right)=\int_{0}^{T} \int_{a}^{b} R e_{2}{ }^{2}\left(x, t ; P_{0}, \ldots, P_{m-1}\right) d x d t$

where $a, b$ and $T$ are elected from the boundaries of the PDEs. In order to find the unknown parameters, one can use

$\frac{\partial J_{i}}{\partial P_{0}}=\frac{\partial J_{i}}{\partial P_{1}}=\cdots=\frac{\partial J_{i}}{\partial P_{m-1}}=0$. 


\section{Illustration}

In this section, we try to show the effectiveness of the proposed method. To do this we will solve the system of partial differential equations with the parameters $p=3, q=2, r=2, s=1$.

One can reasonably use the initial conditions as initial functions

$u(x, 0)=e^{x}$,

$v(x, 0)=e^{-x}$.

Then, progressing as mentioned in the previous section, one can reach the following first order approximate OPIM solutions

$$
\begin{aligned}
& u_{1}=e^{-x} t-\frac{3 t x^{2} P_{0}}{2} \\
& v_{1}=e^{x} t+\frac{3 t x^{2} P_{0}}{2}
\end{aligned}
$$

Similarly, with the help of OPIA and the prefound terms, one can proceed as:

$$
\begin{aligned}
& u_{2}=-e^{-x}-\frac{3 e^{-x} x^{2} P_{0}}{2}-\left(\begin{array}{c}
\frac{3 e^{-x} x^{2}}{2}+\frac{5 x^{3} P_{0}}{2} \\
+\frac{15 e^{-x}}{8} x^{4} P_{0}^{2}
\end{array}\right) P_{1} \\
& v_{2}=t e^{x}+\frac{3 t x^{2} P_{0}}{2}-\left(\begin{array}{c}
-\frac{3 e^{-x} x^{2}}{2}-\frac{7 x^{3} P_{0}}{2} \\
-\frac{17 e^{-x}}{8} x^{4} P_{0}^{2}
\end{array}\right) t P_{1},
\end{aligned}
$$

$$
\begin{aligned}
& u_{3}=u_{2} \\
& -\left(\begin{array}{l}
\frac{3 x^{2}}{2}+\frac{9 x^{3} P_{0}}{2}+\frac{13}{8} t x^{4} P_{0}^{2}+\frac{9 e^{x} t x^{3} P_{1}}{2} \\
+\frac{81}{4} x^{4} P_{0} P_{1}+\frac{243}{8} x^{5} P_{0}^{2} P_{1}+\frac{607 e^{x}}{16} x^{6} P_{0}^{3} P_{1} \\
+\frac{27}{8} x^{4} P_{1}^{2}+\frac{81}{4} x^{5} P_{0} P_{1}^{2}+\frac{1043}{16} e^{x} x^{6} P_{0}^{2} P_{1}^{2} \\
+\frac{729}{16} t x^{7} P_{0}^{3} P_{1}^{2}+\frac{2581}{128} e^{x} t x^{8} P_{0}^{4} P_{1}^{2} \\
+\cdots
\end{array}\right) t P_{2}
\end{aligned}
$$

$$
\begin{aligned}
& v_{3}=v_{2}- \\
& \left(\begin{array}{l}
-\frac{3 t x^{2}}{2}-\frac{9 x^{3} P_{0}}{2}-\frac{13}{8} e^{x} t x^{4} P_{0}^{2}-\frac{9 x^{3} P_{1}}{2} \\
-\frac{73}{4} x^{4} P_{0} P_{1}+\frac{101}{2} t e^{-x} x^{2} P_{0}^{2} P_{1}-\frac{243}{8} x^{5} P_{0}^{2} P_{1} \\
-\frac{243}{16} x^{6} P_{0}^{3} P_{1}-\frac{27}{8} x^{4} P_{1}^{2}-\frac{81}{4} x^{5} P_{0} P_{1}^{2}- \\
\frac{729}{16} t x^{6} P_{0}^{2} P_{1}^{2}-\frac{729}{16} x^{7} P_{0}^{3} P_{1}^{2}-\frac{2187}{128} x^{8} P_{0}^{4} P_{1}^{2} \\
+\cdots
\end{array}\right) t P_{2}
\end{aligned}
$$

and so on. One can has higher order approximations by going in a similar manner. To obtain the parameters, one has to compute residual. For instance, with the values $T=1, a=$ $0, b=1$ in the Eq. (17) and performing the calculations

$\frac{\partial J}{\partial P_{0}}=\frac{\partial J}{\partial P_{1}}=\frac{\partial J}{\partial P_{2}}=\cdots=0$

We will get $P_{0}=1.08365, P_{1}=0.90863$ and $P_{2}=$ -0.100391 . Substituting these constans into the corresponding approximate solutions, we have the third order OPIM solutions. Figure 3.1 and Figure 3.2 give absolute residual errors (AREs) for 5 th and 7 th order approximate solutions.

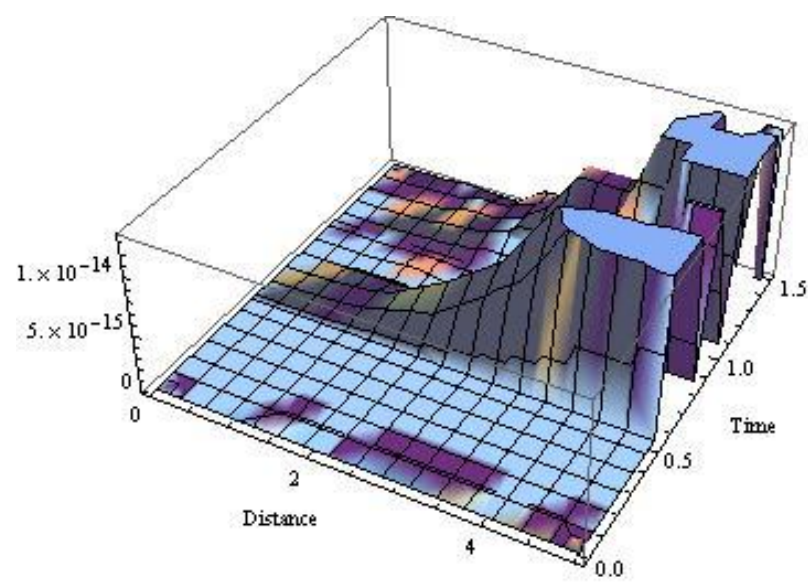

Fig.3.1: AREs for fifth order OPIM solution. 


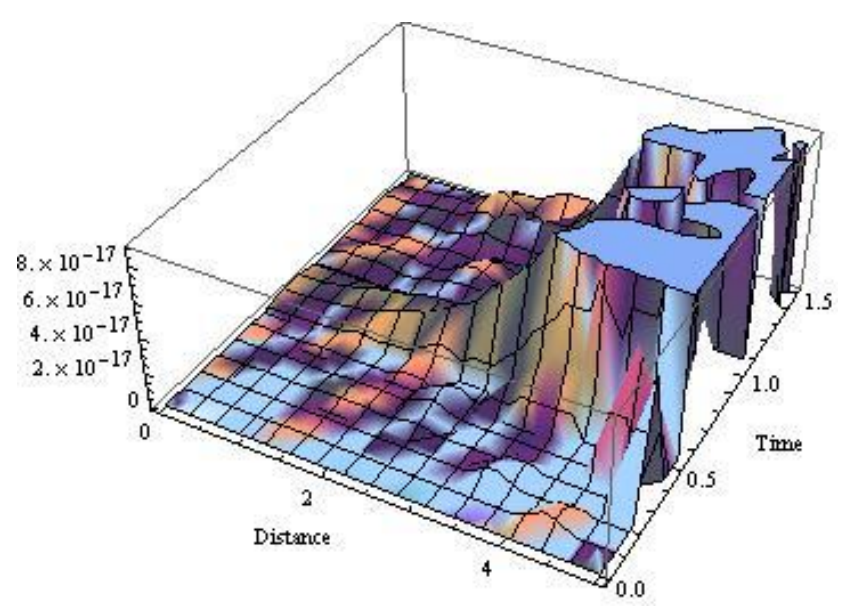

Fig.3.2: AREs for seventh order OPIM solution.

\section{Discussion}

In this paper, we implement and benefit from the lately established OPIM for dealing with the system of particular PDEs. An application is solved in detail to prove the power of the OPIM. Graphics are given to demonstrate the efficiency of optimal technique in higher-order approximations. It is clear that many complex functions and integrations arise when constructing the OPIAs. Thus, we have benefited from Mathematica 9.0. to overcome these difficulties. As a conclusion we can say that the proposed scheme can be safely used as a solver of nonlinear PDEs.

\section{References}

Aktürk, T., Gürefe, Y., Pandır, Y., 2017. An application of the new function method to the Zhiber-Shabat equation, An International Journal of Optimization and Control: Theories \& Applications (IJOCTA), 7(3), 271-274.

Bildik, N., Deniz, S., 2017. A new efficient method for solving delay differential equations and a comparison with other methods, The European Physical Journal Plus, 132(1), 51.

Bildik, N., Deniz, S., 2018. New analytic approximate solutions to the generalized regularized long wave equations, Bulletin of the Korean Mathematical Society, 55(3), 749-762.

Bildik, N., Deniz, S., 2018. Solving the burgers' and regularized long wave equations using the new perturbation iteration technique, Numerical
Methods for Partial Differential Equations, 34(5), 1489-1501.

Bulut, H., Baskonus, H. M., Pandir, Y., 2013. The modified trial equation method for fractional wave equation and time fractional generalized Burgers equation. In Abstract and Applied Analysis (Vol. 2013). Hindawi.

Demiray, S. T., Pandir, Y., Bulut, H., 2016. All exact travelling wave solutions of Hirota equation and Hirota-Maccari system, Optik-International Journal for Light and Electron Optics, 127(4), 1848-1859.

Deniz, S., Bildik, N. 2018. Optimal perturbation iteration method for Bratu-type problems, Journal of King Saud University-Science, 30(1), 91-99.

Deniz, S. 2017. Optimal perturbation iteration method for solving nonlinear heat transfer equations. Journal of Heat Transfer, 139(7), 074503.

Fan, Engui, and Hongqing Zhang., 1998. A note on the homogeneous balance method. Physics Letters $A$ 246(5), 403-406.

İnan, İ.E., 2019. Auto-Bäcklund Transformation for Fifth Order Equation of the Burgers Hierarchy, Afyon Kocatepe Üniversitesi Fen Ve Mühendislik Bilimleri Dergisi, 19, 021301, 328-334.

Inc, M., 2008. The approximate and exact solutions of the space-and time fractional Burgers' equations with initial conditions by variational iteration method, Journal of Mathematical Analysis and Applications, 345(1), 476-484.

Guo, Boling, Liming Ling, and Q. P. Liu., 2012. Nonlinear Schrödinger equation: generalized Darboux transformation and rogue wave solutions, Physical Review E, 85(2), 026607.

Manafian H.J. and Lakestani M.,2013. Solitary wave and periodic wave solutions for variants of the $\mathrm{KdV}$ Burger and the $K(n, n)$-Burger equations by the generalized tanh-coth method, Communations in Numerical Analysis, 1-18.

Manafian H.J. and Zamanpour I.,2013. Analytical treatment of the coupled Higgs equation and the Maccari system via Exp-function method, Acta Universitatis Apulensis, 33, 203-216.

Matveev V.B. and Salle M.A., 1991. Darboux Transformations and Solitons, Springer, Berlin.

Malfliet W., 1992. Solitary wave solutions of nonlinear wave equations, American Journal of Physics, 60, 650-654. 
Shang Y., 2007 Backlund transformation, Lax pairs and explicit exact solutions for the shallow water waves equation. Applied Mathematics and Computation, 187, 1286-1297.

Shen S. and Pan Z.,2003. A note on the Jacobi elliptic function expansion method, Physics Letters A, 308, 143-148.

Wadati, M., Heiji S., and Kimiaki K., 1975. Relationships among inverse method, Bäcklund transformation and an infinite number of conservation laws. Progress of Theoretical Physics 53(2) , 419-436.

Wazwaz, A.M., 2007. Multiple-soliton solutions for the KP equation by Hirota's bilinear method and by the tanh-coth method. Applied Mathematics and Computation, 190(1), 633-640. 